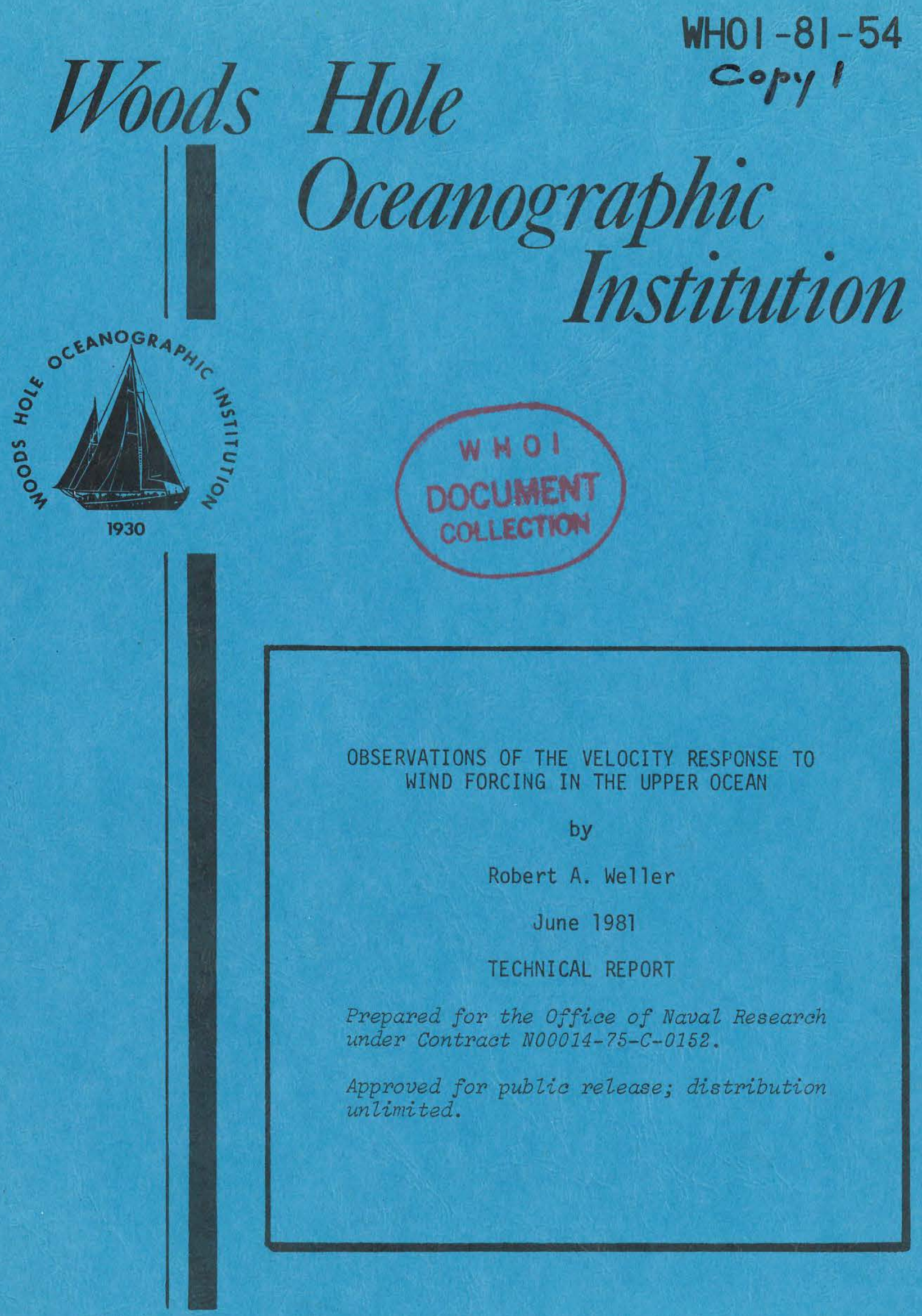

WOODS HOLE, MASSACHUSETTS 02543 
WHOI $-81 \cdot 54$

\author{
OBSERVATIONS OF THE VEL.OCITY RESPONSE TO \\ WIND FORCING IN THE UPPER OCEAN
}

by

Robert A. Weller

WOODS HOLE OCEANOGRAPHIC INSTITUTION

Woods Hole, Massachusetts 02543

June 1981

TECHNICAL REPORT

Prepared for the Office of Naval Research under lontract N00014-75-C-0152.

Reproduction in whole or in part is permitted for any purpose of the United States Govermment. In citing this

report in a bibliography the reference given should be to: Journal of Geophysical Research 86(C3): 1969-19'? (Mar.sh 20, 1981).

Approved for public release; distribution unlimited.

Approved for Distribution: Valentine Worthington, Chairman Department of Physical Oceanography 


\title{
Observations of the Velocity Response to Wind Forcing in the Upper Ocean
}

\author{
ROBERT A. WELLER \\ Woods Hole Oceanographic Institution, Woods Hole, Massachusetts 02543

\begin{abstract}
The response of the horizontal velocity field to forcing by the local wind was observed in the upper 150 $\mathrm{m}$ of the ocean by profiling with vector measuring current meters from the Research Platform Flip as it drifted off the coast of California in January 1977. In the mixed layer, approximately $50 \mathrm{~m}$ deep, motion at frequencies lower than $0.1 \mathrm{cph}$ was coherent with the wind stress. Rotary cross spectral analysis showed that the shear in the surface layer was related to the local wind stress and that the structure of the response at low frequencies was similar to but did not agree completely with the predictions of simple linear, eddy viscosity models.
\end{abstract}

\section{INTRODUCTION}

To determine the extent to which the horizontal velocity field in the upper ocean is related to the local wind a field experiment was conducted with profiling current meters deployed from the Research Platform Flip. Hunkins [1966], Halpern [1974], Gonella [1972], and others have shown that the velocity field in the mixed layer, to some extent, has the spirallike structu with flow to the right of the wind stress, predicted by Ekman [1905]. In this experiment a stable platform, Flip, and current meters specifically designed for use in the upper ocean, vector measuring current meters (VMCMs) [Weller and Davis, 1980], were used to investigate further the relationship between mixed layer velocities and the local wind.

The method of instrument deployment is summarized in the next section. Some details of the deployment scheme, not crucial to the analysis of the data, are provided in the appendix. An overview of the data and a quantitative measure of the relation between the velocity field and the local wind stress are presented in the third section. Rotary cross spectral analysis is used to identify the component of the observed velocity field linearly related to the wind stress. Because Flip's drift was not well known at high frequencies, further analysis of the structure of the observed velocity field uses the observed shear which was independent of Flip's drift. Conclusions and a few remarks are given in the final section.

\section{DATA ACQUISITION}

The goal of the data acquisition effort was to obtain, in the upper $150 \mathrm{~m}$ of the ocean, horizontal velocity data to examine the vertical structure of the velocity field at frequencies near and less than the inertial frequency. One possible strategy would have been to place current meters at various fixed levels in a surface mooring. This strategy was not chosen because the current meters were not yet equipped with vector averaging electronics and would had to have sampled frequently (and had short deployment life) to avoid error from surface wave and mooring motions and because with only four instruments available, vertical resolution would have been poor. Instead, the method used was to profile with the current meters from Flip, giving good vertical resolution, while sampling very rapidly to minimize measurement error. Flip is essentially a very large spar buoy, free from high frequency motions. (See Regier [1975]) for a discussion of Flip's response to wave motion.)

Copyright (c) 1981 by the American Geophysical Union.
The cu: nt meters were early versions of the vector measuring current meter (VMCM) then under development for use in the upper ocean. The instrument and its performance characteristics have been described by Davis and Weller [1980] and Weller and Davis [1980]. All versions of these instruments, as shown in Figure 1, have two cosine response propeller sensors mounted at right angles and an internal compass. The instruments deployed from Flip in 1977 recorded internally on cassette tape the revolutions of both propellers during each sampling interval. The pressure and the instrument heading were also recorded at the end of each interval. Though the instruments lacked vector-averaging electronics, it was possible to minimiz error in the velocities calculated from the timeaveraged, peller revolutions and instantaneous heading by keeping the sampling interval small compared to the periods of fluctuation in flow direction or instrument heading. This rapid sampling exhausted the VMCM battery in 1 day; hence, the instruments were recovered and redeployed on a daily basis.

The four VMCMs, as shown in Figure 1, were attached in two pairs to a winch cable led over a sheave at the end of a 15 $\mathrm{m}$ long boom that projected ahead and to the port side of Flip. The instruments in each pair were $4 \mathrm{~m}$ apart, and the two pairs were separated by $68 \mathrm{~m}$. The winch cycled automatically, paying out and then retrieving approximately $65 \mathrm{~m}$ of wire. Hence, the top instrument of the upper pair cycle hetween 5 and $70 \mathrm{~m}$ depths, and the bottom instrument ie lower pair cycled between 77 and $142 \mathrm{~m}$ depths. During descent and ascent the winch stopped at 10 preset depths, holding the instruments at fixed levels for approximately $5 \mathrm{~min}$. A complete cycle, descent followed by ascent, was accomplished in 2 hours. The result of the sampling scheme was unevenly spaced time series of horizontal velocity at 21 levels in the upper $142 \mathrm{~m}$. More detail about the sampling scheme is given in the appendix.

The profiling was carried out while Flip drifted freely some $550 \mathrm{~km}$ southwest of San Diego, California. The location provided deep water and a site removed from the coastal currents. During the experiment, which ran from January 13-28, 1977, Flip drifted west northwest (Figure 2). Flip's position was monitored with Loran A; but, on average, only two good fixes were obtained per day. Wind measurements were made using Flip's anemometer, a cup and vane mounted on a mast above the hull some $18 \mathrm{~m}$ above the sea surface, and were recorded every half hour. Wind velocities were logarithmically corrected to a height of $10 \mathrm{~m}$, and wind stress was calculated using a quadratic relation and a drag coefficient of $1.3 \times 10^{-3}$ 

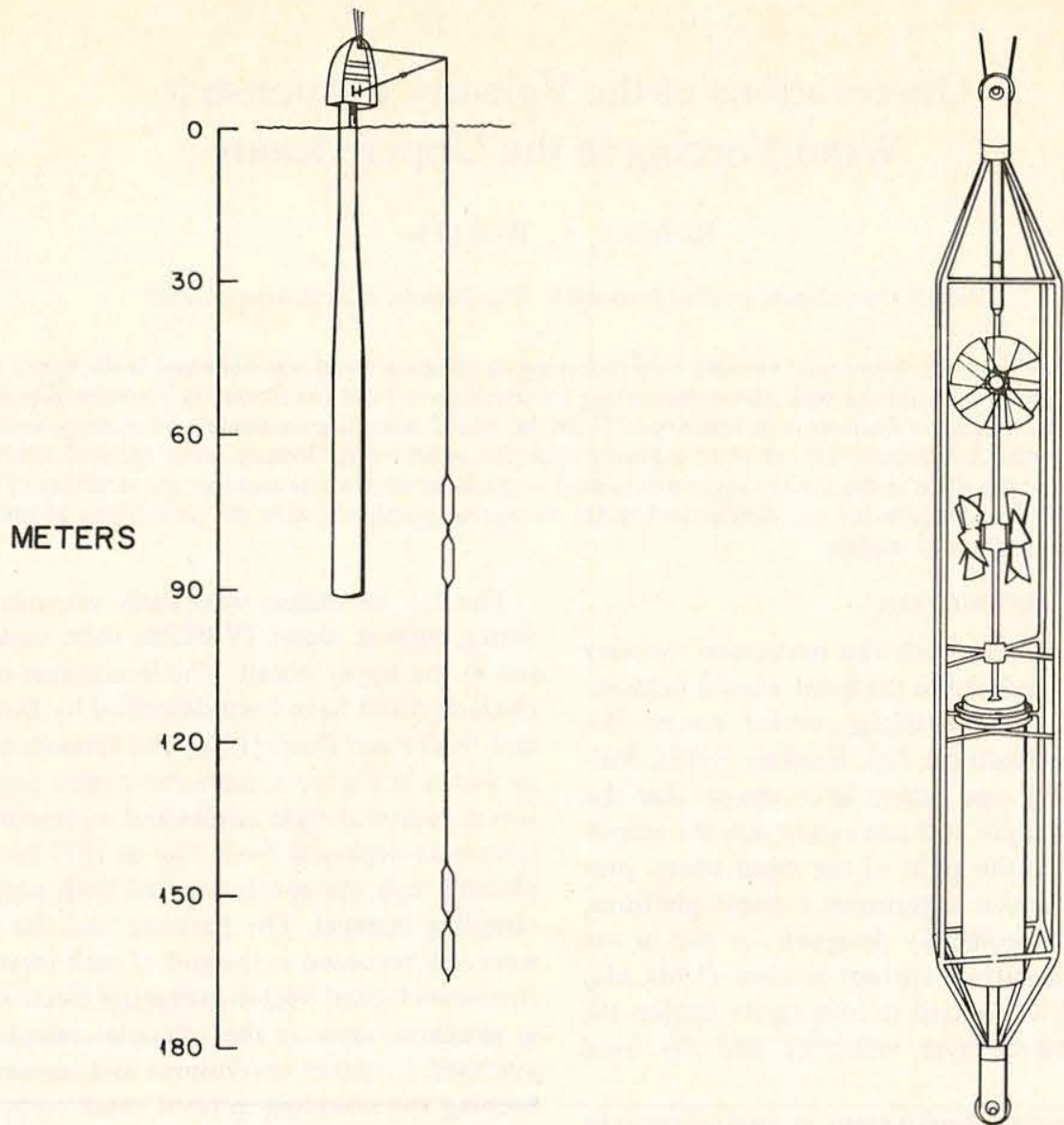

Fig. 1. Current meter array deployed from Flip. Four VMCMs (a detailed drawing of a VMCM is shown to the right) were suspended on the wire of a profiling winch; they were grouped in two pairs as shown, but are not drawn to scale. A single VMCM is $2.5 \mathrm{~m}$ in length.

Balmy weather and light, steady winds typically from the north or south, prevailed.

Little information about the density structure of the upper ocean and none about the buoyancy flux was obtained to accompany the velocity data; as a result, this paper does not attempt to evaluate the effect of stratification in the upper ocean. Three XBTs, taken on the January 17, 22, and 28, 1977, showed an isothermal layer extending from the surface to approximately $55 \mathrm{~m}$.

\section{OBSERVED VELOCITIES}

Mean flow was to the west northwest. The mean (E,N) velocity vector of Flip's drift was $\left(-6.4 \mathrm{~cm} \mathrm{~s}^{-1}, 2.0 \mathrm{~cm} \mathrm{~s}^{-1}\right)$, while the mean flow relative to Flip, averaged over all depths, was $\left(2.0 \mathrm{~cm} \mathrm{~s}^{-1}, 0.2 \mathrm{~cm} \mathrm{~s}^{-1}\right)$. Flip's hull extends approximately 90 $\mathrm{m}$ below the water line, but wind drag on the portion above the water line causes the platform to sail downwind. As Flip drifted, large relative velocities were observed roughly $180^{\circ}$ out of phase with and proportional to the wind stress.

Time series of complex relative horizontal velocity (relative to Flip), $U(t)=u(t)+i v(t)$, were formed for each of the 21 depths. Complex covariance functions were calculated according to the formula

$$
C(T)=\left[\frac{\left\langle U(t) U^{*}(t+T)\right\rangle}{\langle|U(t)|\rangle^{1 / 2}\langle|U(t+T)|\rangle^{1 / 2}}\right] \cdot \operatorname{var}
$$

where var is the variance of the time series over the total 14 day period, where $|U(t)|$ is the magnitude of the complex ve- locity vector $U(t)$, and where the angle brackets denote an average taken over all times $t$ when a value of $U(t)$ and $U(t+T)$ exists. $T$ is the time lag. Capital letters denote complex vectors; the $x$ (east-west) axis is the real axis, and the $y$ (northsouth) axis is the imaginary axis. The complex covariance functions were then Fourier transformed to obtain rotary spectra which decomposed the velocity variance of the data into clockwise and counterclockwise rotating components of various frequencies [Gonella, 1972]. Rotary autospectra of velocities from within certain depth ranges could not be distinguished from one another when plotted. Ajdacent depths were therefore grouped together, defining six depth ranges (Figure 3). Depth range one included data from the 5,10 , and $15 \mathrm{~m}$; depth range two, from $22,30,36$, and $40 \mathrm{~m}$; depth range three, from 48, 56, 62, and $67 \mathrm{~m}$; depth range four, from 76, 83, and $89 \mathrm{~m}$; depth range five, from 96,104 , and $110 \mathrm{~m}$; and depth range six, from $118,126,134$, and $142 \mathrm{~m}$. The number of degrees of freedom increased with frequency, $\omega$, owing to band averaging and for $\omega$ in cph were roughly equal to $360 \cdot \omega$ for a spectrum calculated from the data from four of the original 21 levels.

Clockwise oscillatory motion with a spectral peak near $-0.04 \mathrm{cph}$ (negative frequencies correspond to the clockwise rotating components) was present at all depths. It was small in amplitude near the surface, slightly larger below the mixed layer, then dominant below $89 \mathrm{~m}$, and showed a $180^{\circ}$ change in phase across the base of the mixed layer. The motion is thought to be inertial, because of its clockwise sense of rota- 


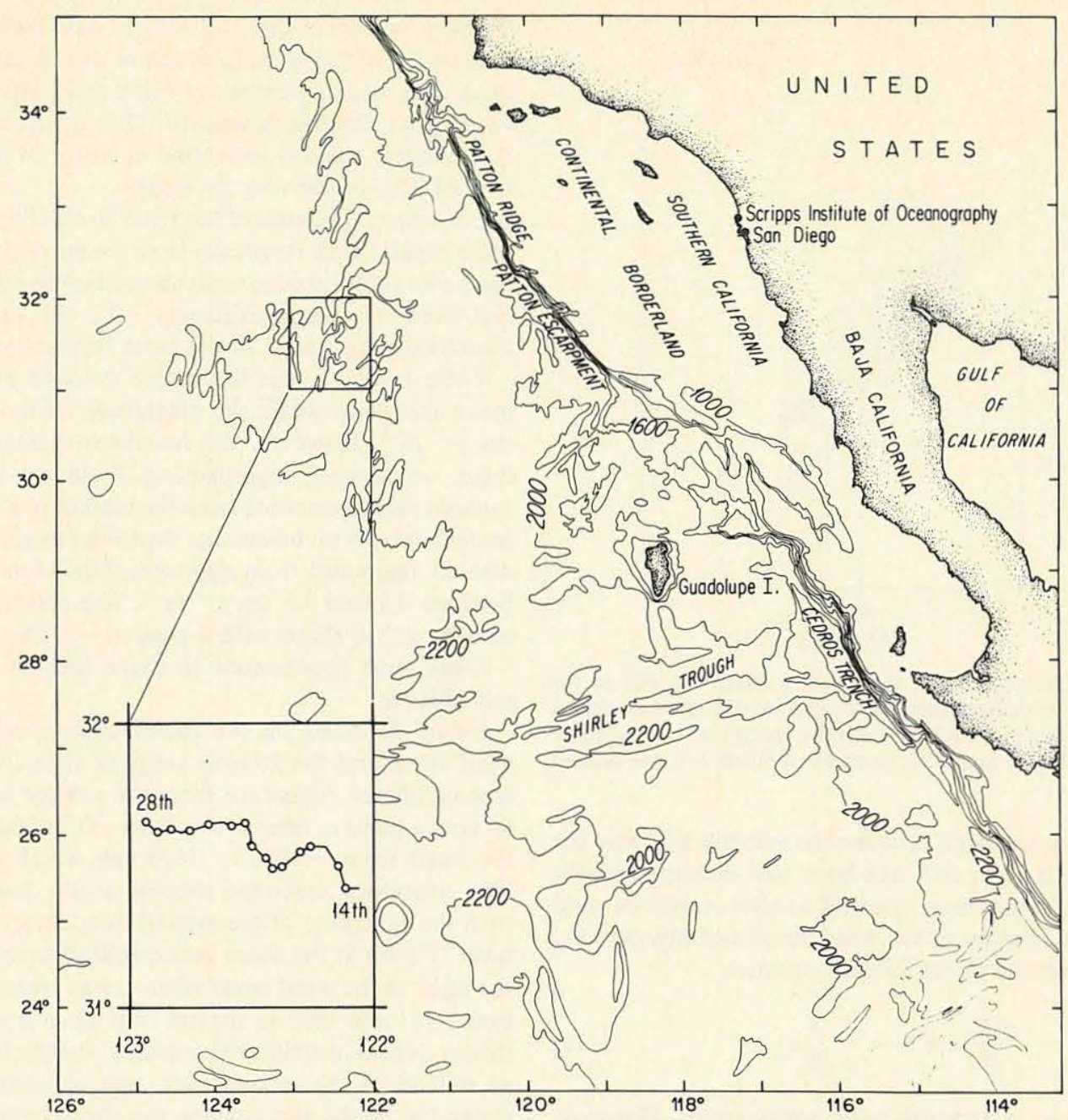

Fig. 2. Flip's initial position southwest of San Diego and subsequent drift (see inset).

tion and nearness to the local inertial frequency of -0.0435 cph. In contrast, on the basis of current meter measurements reviewed by Munk et al. [1970] from off the San Diego coast, the local tidal currents describe counterclockwise turning ellipses with the major axis parallel to shore; the amplitude of the diurnal tide is only on the order of $1 \mathrm{~cm} \mathrm{~s}^{-1}$ while that of the semidiurnal tide is on the order of $2 \mathrm{~cm} \mathrm{~s}^{-1}$. (Additionally, below the mixed layer the cross spectra discussed below showed clockwise rotation of the velocity vector with depth at inertial frequency. As explained by Leaman [1975], the clockwise rotation indicates the downward flux of energy associated with a propagating near inertial internal wave.)

Coherence squared, $\gamma_{1,2}{ }^{2}$, was calculated as

$$
\gamma_{1,2}^{2}(\omega)=\frac{\left|\operatorname{RCS}_{1,2}(\omega)\right|^{2}}{\operatorname{RS}_{1}(\omega) \operatorname{RS}_{2}(\omega)}
$$

where $\operatorname{RCS}_{1,2}(\omega)$ was the rotary cross spectrum of the time series at depth 1 and 2 and $\operatorname{RS}_{1}(\omega)$ and $\operatorname{RS}_{2}(\omega)$ were the corresponding autospectra. Phase, the most probable angle between simultaneous rotary components of the two time series, was calculated as

$$
\phi_{1,2}(\omega)=\tan ^{-1}\left[\frac{\operatorname{Im}\left[\operatorname{RCS}_{1,2}(\omega)\right]}{\operatorname{Re}\left[\operatorname{RCS}_{1,2}(\omega)\right]}\right]
$$

(Positive phases indicate that the component of series 2 was to the right of that of series 1.) Figures $4 a, 4 b, 4 c$, and $4 d$ summa- rize the results of the cross spectral analysis. The statistical significance of the rotary cross spectral analysis was determined using formulae given by Jenkins and Watts [1969]. On the basis of considerations of the confidence intervals, values of coherence squared are shown only when they are greater than or equal to 0.4 , typically with contour intervals of 0.2 , and phases are shown only when coherence squared is greater than or equal to 0.5 , with $10^{\circ}$ contour intervals.

The relative motion near the surface was significantly coherent over a band from approximately -0.1 to $0.1 \mathrm{cph}$ with motion over a depth range from the surface to $40 \mathrm{~m}$. In the surface layer, phase changed with depth at subinertial frequencies. In the first 5 days in particular, as shown by the daily means, current tended to rotate to the right with depth. Other than at near-inertial frequencies and in the surface layer, the only coherence over depth was seen in the relative motion at low frequencies, roughly between -0.02 and 0.02 $\mathrm{cph}$. The motion was not significantly coherent across the thermocline, even though the drift of Flip contributed a depth independent component to the flow.

\section{RELATION OF THE OBSERVED Velocities TO THE LOCAL WIND}

For low frequencies the observed velocity field was coherent over the mixed layer and the velocity turned to the right with depth. The turning with depth (Figure 5) suggested that 


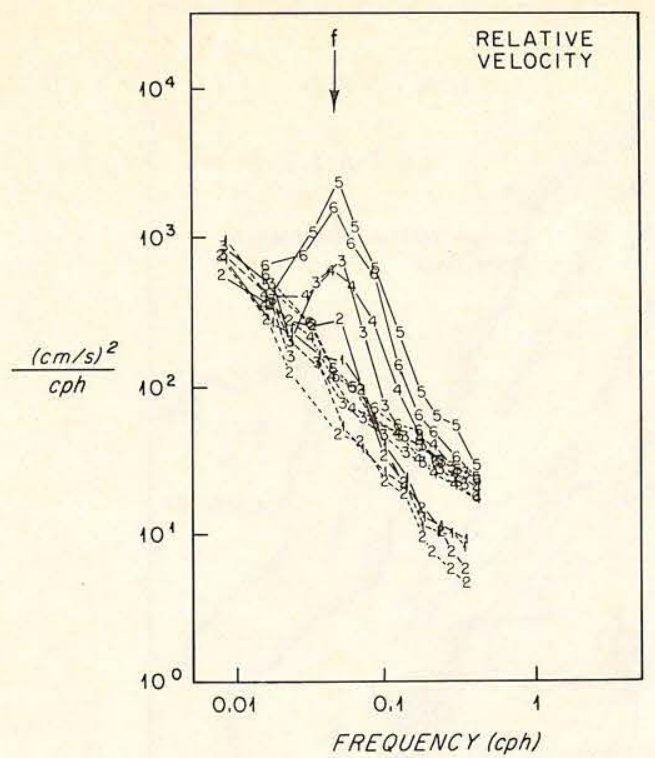

Fig. 3. Rotary autospectra of the velocity relative to Flip in the six depth ranges. The dashed lines are the spectra of counterclockwise $(+f)$ components, and the solid lines are the spectra of the clockwise $(-f)$ components. Depth ranges, denoted by numbers $1-6$, are defined in the text.

a significant relation existed between the velocity field and the local wind stress. If Flip's drift had been well measured or if it had been steady, rotary cross spectral analysis could be used to investigate the relation of the wind stress and absolute velocity, and the validity of the Ekman equation,

$$
\frac{\partial U}{\partial t}+i f U=\frac{1}{\rho} \frac{\partial}{\partial z} \tau
$$

where $\tau=\tau_{x}+i \tau_{y}$, a complex wind stress vector. However, Flip's position was known only twice per day; and the validity of (1) for $U$, the absolute velocity, could be checked at fre- quencies no higher than 1 cycle per day. Instead, the relation of the wind to the velocity structure was investigated by creating a data set independent of Flip's drift. Flip's drift was time varying but depth independent. Thus the 21 time series, $U\left(z_{n}\right.$, $t$ ), of relative velocity were used to create 20 time series, $D\left(z_{m}\right.$, $t)=\Delta U / \Delta z$, of the velocity shear.

The rotary spectrum of the wind stress (Figure 6) decreased more rapidly with frequency than the current spectra, and the clockwise rotary components showed more energy at frequencies from $-f$ to approximately $-0.2 \mathrm{cph}$ than the counterclockwise components in the same frequency band.

Table 1 summarizes the simple statistics of the shear. The mean shear was weak; the magnitude rarely greater than 0.1 $\mathrm{cm} \mathrm{s}^{-1} \mathrm{~m}^{-1}$. However, the maximum values of shear were large, occasionally approaching $3 \mathrm{~cm} \mathrm{~s}^{-1} \mathrm{~m}^{-1}$. The mean squared shear decreased from the surface to a minimum at approximately $26 \mathrm{~m}$; below that depth the mean square shear increased again and from approximately $44 \mathrm{~m}$ down remained between 0.3 and $1.5 \mathrm{~cm} \mathrm{~s}^{-1} \mathrm{~m}^{-1}$. The spectra (Figure 7) are close to $\omega^{-1}$ in shape with a peak at $-f$. The spectral peak at $-f$ was most pronounced in shear spectra from below the mixed layer.

Figure 8 , based on the rotary cross spectra between the wind stress and the 20 time series of shear, shows that there was significant coherence from the surface to approximately $40 \mathrm{~m}$ in a band of frequencies from -0.2 to $0.2 \mathrm{cph}$ (excluding the band from -0.006 to $0.006 \mathrm{cph}$ which was unresolved). The coherence extended deepest at the lowest frequencies, with the exception of the inertial frequency, $-f$. In the mixed layer (Figure 9) the shear vector shifted from being slightly to the right of the wind stress when $\omega$ was greater than $-f$ to between $90^{\circ}$ and $160^{\circ}$ to the left of it when $\omega$ was less than $-f$. (Shear at near-inertial frequencies at depths from 80 to $150 \mathrm{~m}$, as well as in the mixed layer, was coherent with the wind stress; below the thermocline the shear vector rotated clockwise with depth. A possible explanation is that by Ekman suction, the local wind generated downward propagating near-in-
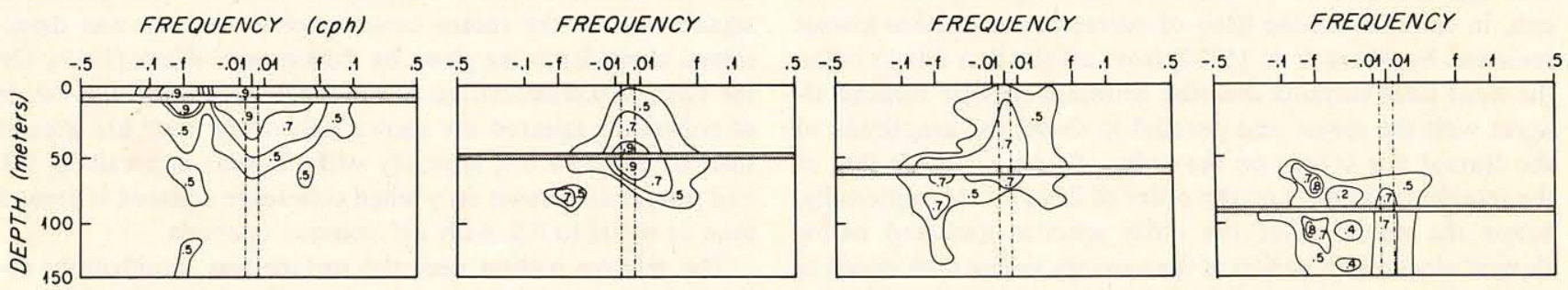

\section{COHERENCE SQUARED}

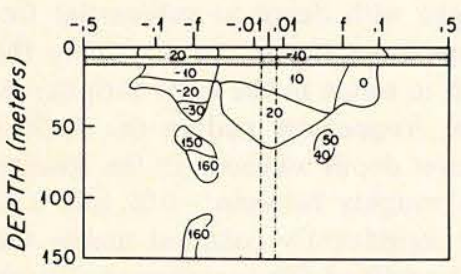

a.
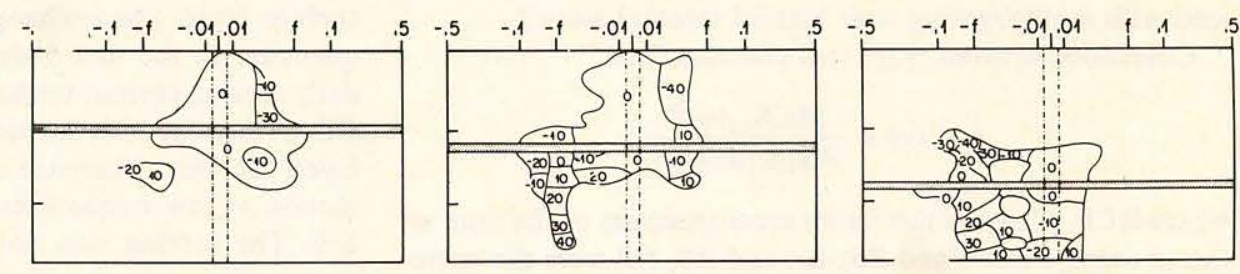

PHASE, IN DEGREES b.
C.

Fig. 4. Coherence squared and phase between the relative velocity at one of the 21 levels and that at the other depths: (a) between $10 \mathrm{~m}$ and all other depths, (b) between $48 \mathrm{~m}$ and all other depths, (c) between $62 \mathrm{~m}$ and all other depths, and (d) between $89 \mathrm{~m}$ and all other depths. Negative angles indicate the velocity was to the right of that at the shaded depth. The low frequencies not resolved are delineated by the vertical dashed lines in this and following figures. 

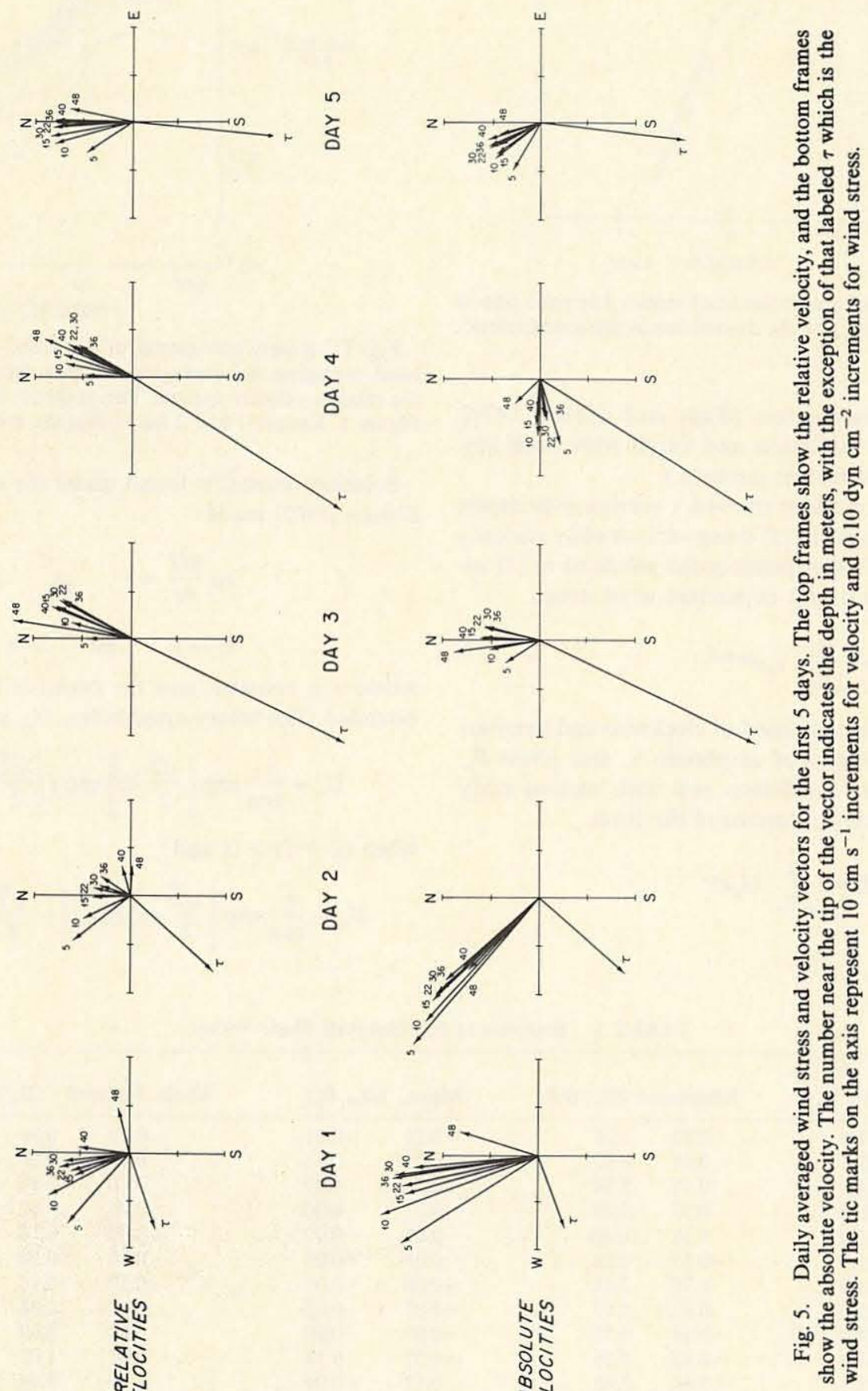


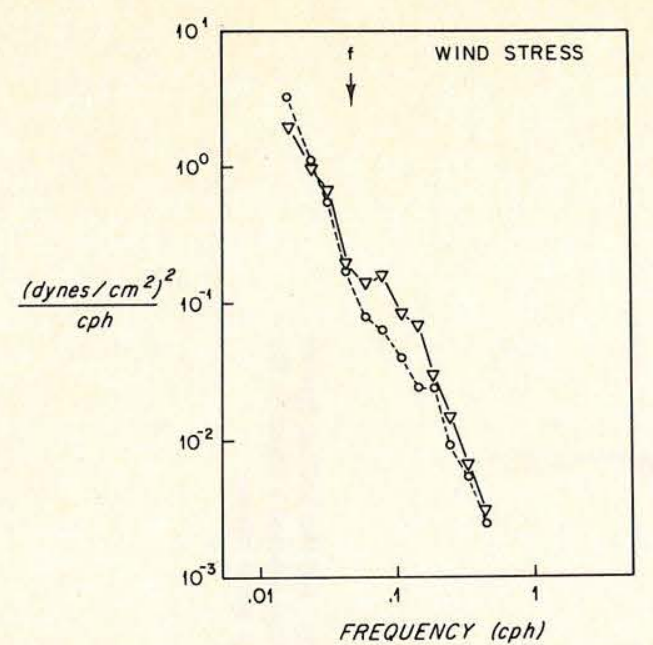

Fig. 6. Rotary autospectrum of the wind stress. The solid line is the clockwise $(-\omega)$ spectrum, and the dashed line is the counterclockwise $(+\omega)$ spectrum.

ertial waves in the thermocline [Käse and Olbers, 1979]. Because the frequency resolution and depth were both limited, this notion was not further pursued.)

Because the Flip observations showed a veering with depth, a feature found in solutions to (1) using various eddy viscosity parameterizations, we further investigated solutions to (1) using $\tau / \rho=\nu \partial U / \partial z$ when a time dependent wind stress,

$$
\tau=\sum_{\omega=-\infty}^{\infty} \tau_{\omega} e^{i\left(\omega t+\theta_{\omega}\right)}
$$

was applied. The stress is composed of clockwise and counterclockwise rotary components of amplitude $\tau_{\omega}$ and phase $\theta_{\omega}$. Under various boundary conditions and with various eddy viscosity parameterizations, solutions of the form,

$$
U=\sum_{\omega=-\infty}^{\infty} U_{\omega} e^{i \omega t}
$$

were sought.

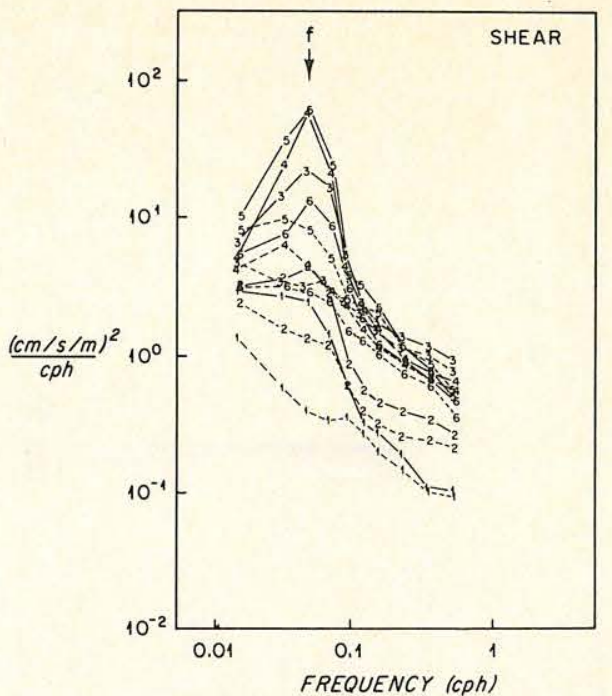

Fig. 7. Rotary autospectra of the shear, computed with the same band averaging and averaging within a depth range as discussed for the relative velocity spectra. The notation for depth ranges is as for Figure 3. Ranges 1 and 2 fall within the mixed layer.

Solutions were first found under the same assumptions that Ekman [1905] made:

$$
\begin{aligned}
& \nu \rho \frac{\partial U}{\partial z}=\tau \quad \text { at } \quad z=0 \\
& U \rightarrow 0 \quad \text { as } \quad z \rightarrow-\infty
\end{aligned}
$$

where $\nu$ is constant and the ocean is homogeneous and unbounded. The rotary amplitudes, $U_{\omega}$, are

$$
U_{\omega}=\frac{\tau_{\omega}}{\nu \rho a} \exp \left(\frac{\sqrt{2}}{2} a z\right) \exp i\left(\frac{\sqrt{2}}{2} a z+\theta_{\omega}-\pi / 4\right)
$$

when $(\omega+f)>0$, and

$$
U_{\omega}=\frac{\tau_{\omega}}{\nu \rho a} \exp \left(\frac{\sqrt{2}}{2} a z\right) \exp i\left(-\frac{\sqrt{2}}{2} a z+\theta_{\omega}+\pi / 4\right)
$$

TABLE 1. Statistics of the Observed Shear Vector

\begin{tabular}{crrrrrr}
\hline & & & & & & \\
Depth, m & \multicolumn{1}{c}{ Maximum $\left(D_{x}, D_{y}\right)$} & Mean & $\left(D_{x}, D_{y}\right)$ & Mean Squared & $\left(D_{x}{ }^{2}, D_{y}{ }^{2}\right)$ \\
\hline 7.5 & 0.93 & 1.26 & -0.21 & -0.01 & 0.27 & 0.29 \\
12.5 & 0.91 & 0.93 & -0.06 & 0.13 & 0.18 & 0.20 \\
18.5 & 0.51 & 1.14 & -0.04 & 0.00 & 0.10 & 0.14 \\
26.0 & 0.51 & 0.80 & -0.03 & 0.00 & 0.06 & 0.07 \\
33.0 & 1.31 & 0.60 & -0.04 & -0.02 & 0.14 & 0.16 \\
38.0 & -0.51 & 1.28 & -0.07 & -0.05 & 0.25 & 0.26 \\
44.0 & 1.78 & 2.48 & -0.06 & -0.05 & 0.57 & 0.74 \\
52.0 & 0.97 & 1.67 & -0.03 & 0.03 & 0.38 & 0.38 \\
59.0 & 2.38 & 0.53 & -0.09 & -0.09 & 0.60 & 0.69 \\
64.5 & -0.45 & 1.66 & -0.02 & 0.14 & 0.93 & 1.07 \\
71.5 & 1.61 & 2.43 & 0.13 & -0.04 & 0.45 & 0.56 \\
79.5 & 1.37 & 2.35 & 0.00 & -0.04 & 0.43 & 0.37 \\
86.0 & 2.51 & 2.46 & 0.16 & 0.05 & 0.84 & 1.39 \\
92.5 & 1.21 & 1.82 & 0.01 & 0.06 & 1.04 & 0.76 \\
100.0 & 0.95 & 1.55 & -0.02 & 0.06 & 0.29 & 0.43 \\
107.0 & 1.43 & 1.86 & -0.13 & 0.00 & 0.63 & 0.60 \\
114.0 & 2.71 & 1.41 & 0.14 & -0.02 & 0.57 & 0.47 \\
122.0 & 0.58 & 2.22 & -0.01 & 0.05 & 0.30 & 0.38 \\
130.0 & 1.17 & 1.48 & -0.01 & 0.15 & 0.21 & 0.26 \\
138.0 & 1.06 & 1.32 & 0.01 & 0.01 & 0.24 & 0.29 \\
\hline
\end{tabular}

Shear has units of $\mathrm{cm} \mathrm{s}^{-1} \mathrm{~m}^{-1}$ 


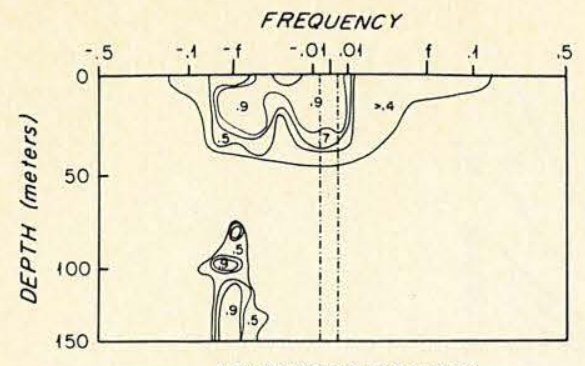

COHERENCE SQUARED

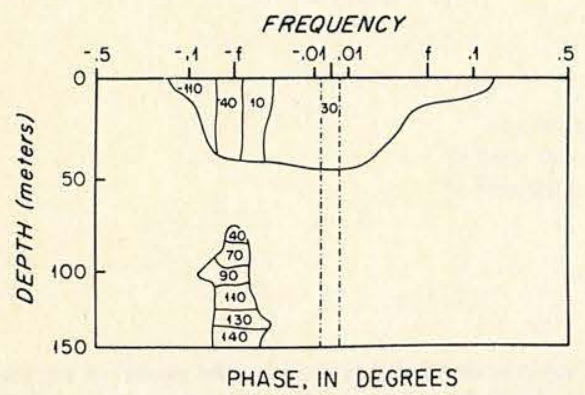

Fig. 8. Coherence (top) and phase (bottom) between the wind stress and the shear. Positive angles indicate shear is to the right of the wind stress.

when $(\omega+f)<0$, and where $a=(|\omega+f| / \nu)^{1 / 2}$. This solution has the familiar exponential decay and veering with depth; veering is to the right with depth when $(\omega+f)>0$ and to the left when $(\omega+f)<0$. By using $(2 a)$ and $(2 b)$ with the rotary amplitudes of the observed wind stress, $U_{\omega}$ was calculated for the 21 levels of observations. Then $D_{\omega}$, the shear, was calculated so that the phase of $\tau$ and the predicted shear could be compared to the phases of the observations (Figure 9). Increasing the eddy viscosity decreased the rate of rotation of the shear vector with both depth and frequency (Figure 10).

The observed phases are close to the phases predicted by the unbounded ocean with eddy viscosity of between 100 and $500 \mathrm{~cm}^{2} \mathrm{~s}^{-1}$. However, the solutions $(2 a),(2 b)$ give velocities and shears that decay exponentially with depth; and while ob- served rotary auto spectrum of shear at $7.5 \mathrm{~m}$ had a level similar to the predicted spectrum at $7.5 \mathrm{~m}$ when the eddy viscosity was taken to be $50 \mathrm{~cm}^{2} \mathrm{~s}^{-1}$ (Figure 11), the rotary auto spectra of observed shear (Figure 7) do not decay with depth in the mixed layer as do the predicted spectra of wind forced shear. At the depth $\pi \sqrt{2} a^{-1}$, the solutions for the unbounded ocean decay to $e^{-\pi}$ and the wind-driven velocity is reversed relative to the surface flow. This depth, for $\omega=0$, is called the Ekman depth. Here, $\pi \sqrt{2} a^{-1}$ will here be associated with the term 'the depth of frictional influence.' $\sqrt{2} a^{-1}$ varies with frequency and eddy viscosity (Figure 12). It is deepest at the inertial frequency, shoals as the absolute value of $(\omega+f)$ increases, and is deeper when the eddy viscosity is larger.

Other simple parameterizations of eddy viscosity, decreasing linearly with depth as suggested by Munk and Anderson [1948] and Thomas [1975] or increasing linearly with depth as suggested by Madsen [1977] were tried. The general solutions for $U_{\omega}$ are Kelvin functions, and exponential decay of velocity and shear with depth is still a feature. When boundary conditions of $\nu \rho \partial U / \partial z=\tau$ at $z=0$ and $U=0$ at $z=-h$ (i.e., a finite depth Ekman layer) are applied to (1) a wind driven shear that changes little in magnitude with depth and that veers less with depth is predicted only when the depth of frictional influence, $\sqrt{2} a^{-1}$, is large compared to $h$. A choice of $h$ to be 50 $\mathrm{m}$ to match the observed mixed layer depth and a choice of $\nu$ to be $500 \mathrm{~cm}^{2} \mathrm{~s}^{-1}$ to match predicted and observed phases gives solutions to (1) that do not differ greatly from the solutions for the unbounded ocean; the predicted shear decays much more rapidly with depth than the observed shear. A choice of a smaller eddy viscosity, in order to match the amplitudes of predicted and observed shear, makes $\sqrt{2} a^{-1}$ smaller. Only when the layer depth, $h$, is less than approximately one tenth of the depth of frictional influence do the finite depth solutions show slow change rather than exponential decay with depth.

At low frequencies, then, the phase angle of the shear vector with respect to the stress vector shows change with depth and frequency that suggests a relatively high eddy viscosity, of the order of $500 \mathrm{~cm}^{2} \mathrm{~s}^{-1}$. In contrast, the amplitude of the observed shear near the surface agrees best with predictions of a

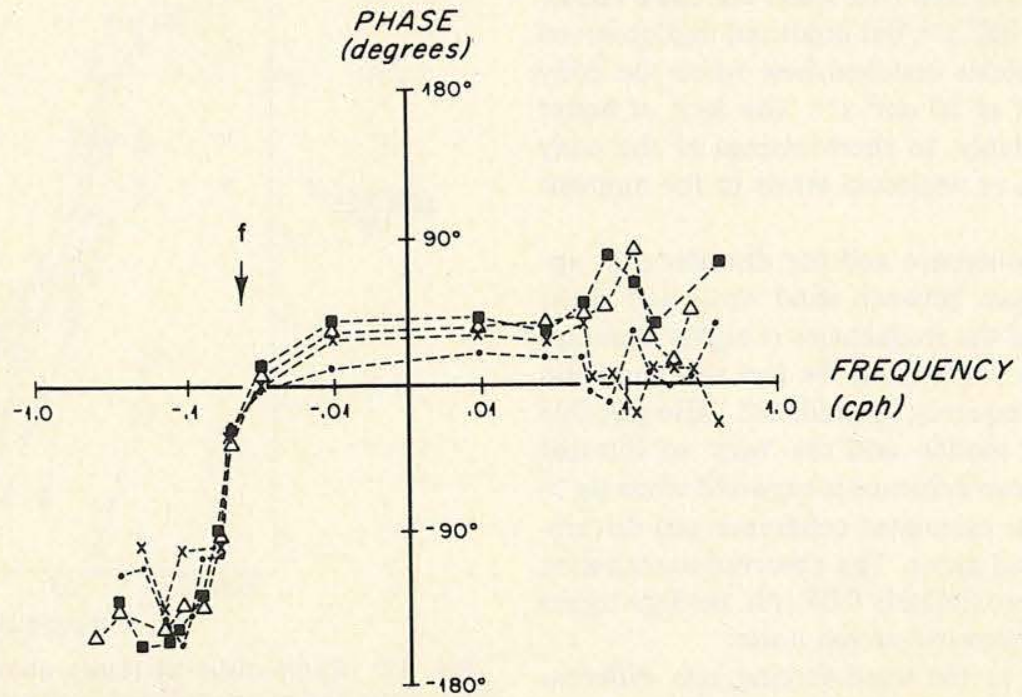

Fig. 9. Plot of the phase between the wind stress and the shear at four depths in the mixed layer. The symbols solid circle, cross, triangle, and solid square, represent the phase at depths of $7.5,12.5,18.5$, and $26.0 \mathrm{~m}$, respectively. Note that at low frequencies phase increases continuously with depth. 


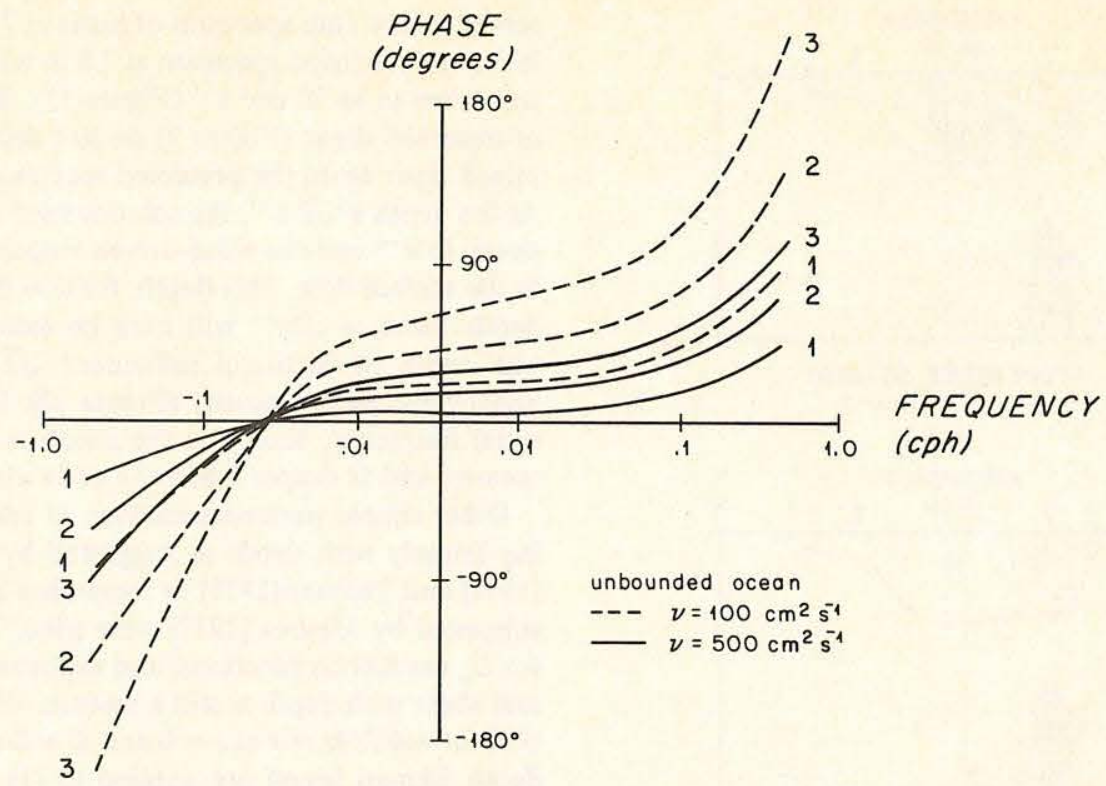

Fig. 10. The phases between the wind stress and the shear vectors at various depths predicted by the model of an unbounded, homogeneous ocean with constant eddy viscosities of $100 \mathrm{~cm} \mathrm{~s}^{-1}$ (dashed lines) and $500 \mathrm{~cm} \mathrm{~s}^{-1}$ (solid lines); 1,2 , and 3 denote phases at the depths of $7.5,12.5$, and $18.5 \mathrm{~m}$, respectively.

wind-driven layer when the eddy viscosity is about $50 \mathrm{~cm}^{2} \mathrm{~s}^{-1}$. The lack of decay with depth in the observed shear is not well modeled.

\section{CONCLUSIONS}

Features of the velocity field in the upper ocean observed from Flip during relatively calm conditions show that the mixed layer responded to the local wind. Because Flip's drift was not well known, the analysis was restricted to relating the vertical shear of the horizontal velocity to the local wind. The velocity shear in a shallow surface layer was coherent with the local wind, and it had the change in phase angle relative to the wind stress at the inertial frequency that is predicted by linear models of wind forced response. However, the shear did not decay with depth nor veer with depth as rapidly as linear models would predict. Nor was a single best value of the eddy viscosity suggested. Phases agreed best when the eddy viscosity was of the order of $500 \mathrm{~cm}^{2} \mathrm{~s}^{-1}$, but predicted and observed near surface shear amplitudes matched best when the eddy viscosity was of the order of $50 \mathrm{~cm}^{2} \mathrm{~s}^{-1}$. The lack of better agreement is due, presumably, to shortcomings of the eddy viscosity parameterization or neglected terms in the momentum equations.

The lack of observed coherence and the disorder that appears in the observed phases between wind stress and shear when the absolute value of the frequencies is higher than approximately $0.06 \mathrm{cph}$ may result from the fact that the wind driven layer shoals with frequency as predicted. Also possible is that semi-diurnal tidal motion and the 'tails' of internal waves [D'Asaro, 1978], whose influence is expected when $|\omega|>$ $f$, are present, reducing the calculated coherence and disturbing the pattern of calculated phase. The observed autospectra tend to level off above approximately $0.06 \mathrm{cph}$, perhaps again showing the influence of nonwind-driven noise.

The observed response to the wind forcing was different from an Ekman layer because shear did not decay exponentially with depth. The observed response had a structure that is also quite different from that proposed in model upper oceans [such as Niiler, 1975] where shear is concentrated near the mixed layer boundaries.

\section{APPENDIX}

In concept the deployment of the current meters as profilers from Flip was simple. The instruments were attached to a wire held off from Flip's hull by a boom and then raised and lowered by a winch, a technique previously used for CTD profiling by Pinkel [1975]. In practice, attention to detail was necessary and the deployment difficult. The details that are important in that they ensure the accuracy of the measurements are summarized here briefly.

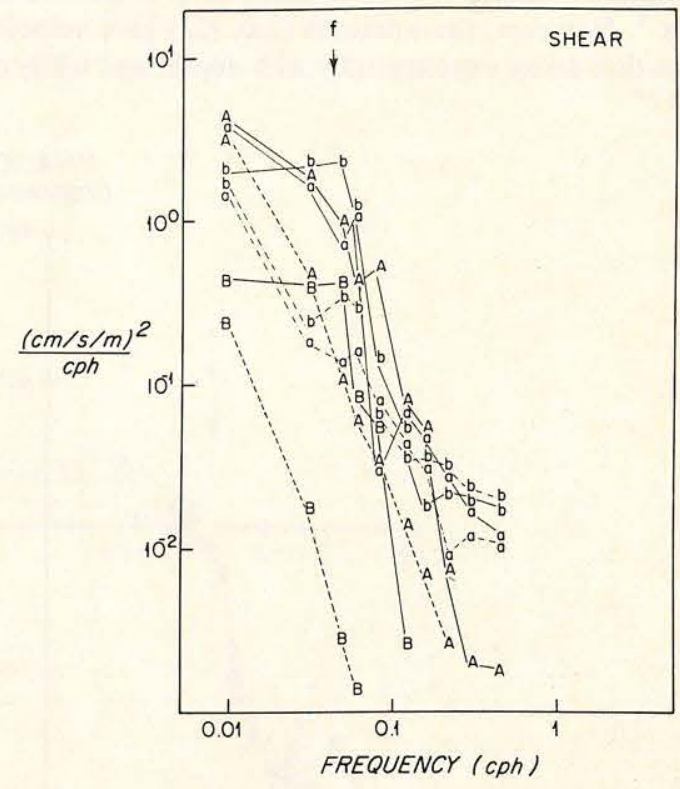

Fig. 11. Comparison of rotary autospectra of observed wind driven shear and those predicted by the mixed layer model when $\nu=$ $50 \mathrm{~cm}^{2} \mathrm{~s}^{-1}$. ' $\mathrm{A}$ ' marks predicted shear amplitudes and ' $\mathrm{a}$ ' the observed shear amplitudes at $7.5 \mathrm{~m}$. 'B' marks the predicted shear amplitudes and 'b' the observed shear amplitudes at $18.5 \mathrm{~m}$. 


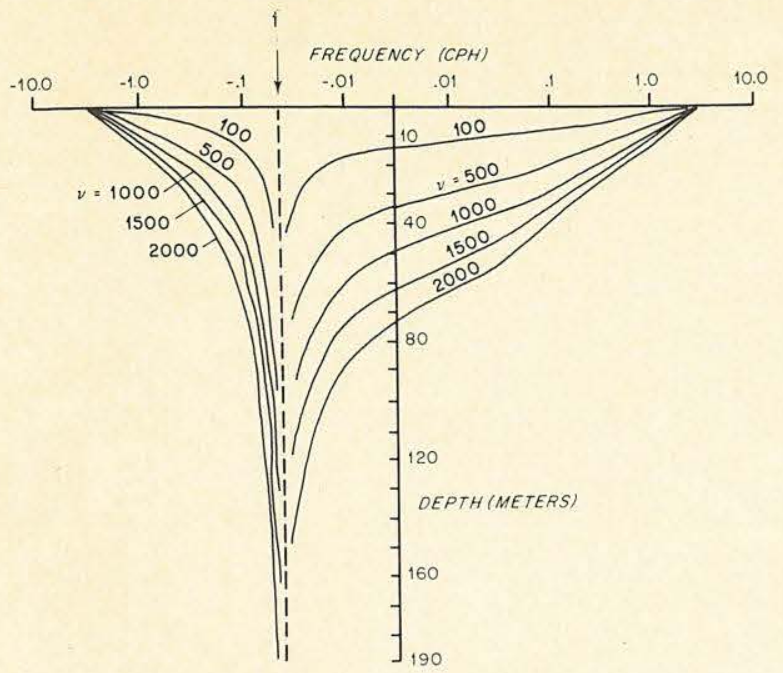

Fig. 12. $\sqrt{2} a^{-1}$, where $a=(|\omega+f| / \nu)^{1 / 2}$, as a function of frequency for the various values of the eddy viscosity shown. The eddy viscosities are in units of $\mathrm{cm}^{2} \mathrm{~s}^{-1}$.

The VMCMs used in the experiment were prototype instruments, with two cosine response propellers mounted orthogonally and an internal flux gate compass, but without vector averaging electronics. At the end of each sample interval, the instrument recorded on cassette tape the pressure, the instantaneous heading, and the number of revolutions during that interval of each propeller. If either instrument or flow direction rotated during the sampling interval, then the use of the instantaneous heading to calculate average flow components would introduce error. Rotation could come from several sources. The VMCM is symmetric about its vertical axis; no fin or other feature is subject to hydrodynamic forces that result in sufficient torque to orient the instrument to the flow. As a result, relatively small torque in the wire can cause the instrument to rotate. The rotation of a VMCM on the wire of the automatic winch was measured in a test cruise; when paying out or recovering wire the instrument rotated continuously, on the order of 2 revolutions in $1.5 \mathrm{~min}$ when raising or lowering at a rate of $5 \mathrm{~m}$ per minute. Much less rotation occurred when the package was held at a fixed level, in which case the instrument heading stayed typically within $7^{\circ}$ of a fixed heading during a $5 \mathrm{~min}$ period. Flip as a whole could rotate, but this motion was minimized by running orientation propellers designed to hold Flip's bearing fixed. Near the surface, however, wave motion rather than package rotation caused the flow direction to vary.

Errors owing to rotation and surface wave motion were minimized by two tactics: sampling rates were very high and data were used only when the instrument was in its 5 min stop at a fixed level and had been there for at least $15 \mathrm{~s}$. The sampling interval was $3.75 \mathrm{~s}$ for instruments at depths of 5-70 m and $7.5 \mathrm{~s}$ for instruments between 77 and $142 \mathrm{~m}$. A consequence of the fast sampling was that the 300 -feet data cassettes filled in 22 hours at the 3.75-s rate. A scheme was arrived at where the instruments could be attached to or removed from the cable without breaking it, allowing instruments to be rapidly removed and brought on board for a new cassette and battery. A schedule was arranged to keep at least two of the four instruments in the water at the same time.

Velocity vectors were computed from the 3.75- and 7.5-s time series of propeller revolutions and instrument heading.
One count was recorded per quarter propeller revolution, corresponding to the passage of $9 \mathrm{~cm}$ of water past the sensor. Laboratory tests [Weller and Davis, 1980] showed that in combinations of mean and oscillatory flows data from the propeller sensor, when averaged over several periods of the oscillatory flow, provided an accurate measure of the mean flow. The velocity data from each $5 \mathrm{~min}$ stop was vector-averaged, and time series of $5 \mathrm{r} \quad \mathrm{a}$ averages were used in the analysis.

Acknowledgments. The field experiment and much of the data analysis were carried out while the author was a graduate student at Scripps Institution of Oceanography, working under the supervision of R. E. Davis and supported by the Office of Naval Research through contract N00014-75-C-0152 with the University of California, San Diego. Further analysis and manuscript preparation were supported by an Institution Fellowship at Woods Hole Oceanog institution. The opportunity to use R. P. Flip was provided by R. Pinkel of Scripps Institution of Oceanography and is gratefully acknowledged. R. Pinkel, J. Price, R. Beardsley, and the reviewers are thanked for their help in improving this paper. $\mathrm{K}$. Bohr is thanked for her typing. This is contribution number 4504 of the Woods Hole Oceanographic Institution.

\section{REFERENCES}

D'Asaro, E. A., Mixed layer velocities induced by internal waves, $J$. Geophys. Res., 83, 2437-2438, 1978.

Davis, R. E., and R. A. Weller, Propeller current sensors, in Air Sea Interaction: Instruments and Methods, edited by F. Dobson, L. Hasse, and R. Davis, pp. 141-154, Plenum, New York, 1980.

Ekman, W. V., On the influence of the earth's rotation on ocean current, Ark. Mat. Astr. Fys., 2, 1-52, 1905.

Gonella, J., A rotary component method for analysing meteorology and oceanographic vector time series, Deep Sea Res., 19, 833-846, 1972.

Halpern, D., Observations of the deepening of the wind-mixed layer in the Northeast Pacific Ocean, J. Phys. Oceanogr., 4, 454-466, 1974.

Hunkins, K., Ekman drift currents in the Arctic Ocean, Deep Sea Res., 13, 607-620, 1966.

Jenkins, G. M. and D. G. Watts, Spectral Analysis and its Applications, pp. 379-380, Holden-Day, San Francisco, Calif., 1969.

Käse, R. H., and D. J. Olbers, Wind driven inertial waves observed during phase III of GATE, Deep Sea Res., GATE Suppl. II, 26, 137$160,1979$.

Leaman, K. D., The vertical propagation of inertial waves in the ocean, Ph.D. Thesis, Woods Hole Oceanogr. Inst., Woods Hole, 1975.

Madsen, O. S., A realistic model of the wind-induced Ekman boundary layer, J. Phys. Oceanogr., 7, 248-255, 1977.

Munk, W. H., and E. R. Anderson, Notes on a theory of the thermocline, J. Mar. Res., 7, 276-295, 1948.

Munk, W., F. Snodgrass, and M. Wimbush, Tides off-shore: Transition from California coastal to deep sea waters, Geophys. Fluid Dyn., 1, 161-235, 1970.

Niiler, P. P., Deepening of the wind-mixed layer, J. Mar. Res., 33, 405-422, 1975.

Pinkel, R., Upper ocean interval wave observations from Flip, J. Geophys. Res., 80, 3892-3910, 1975.

Pollard, R. T., On the generation by winds of inertial waves in the ocean, Deep Sea Res., 17, 795-812, 1970.

Pollard, R. T., and R. C. Millard, Jr., Comparison between observed and simulated wind-generated inertial oscillations, Deep Sea Res., 17, 813-821, 1970.

Regier, L. A., Observations of the power and directional spectrum of oceanic surface waves, Ph.D. Thesis, Univ. of Calif., San Diego, 1975.

Thomas, J. H., A theory of steady wind-driven currents in shallow water with variable eddy viscosity, J. Phys. Oceanogr., 5, 136-142, 1975.

Weller, R. A., and R. E. Davis, A vector measuring current meter, Deep Sea Res., 27, 565-582, 1980.

(Received February 12, 1980; revised October 14, 1980; accepted October 15, 1980.) 


\section{MANDATORY DISTRIBUTION LIST \\ FOR UNCLASSIFIED TECHNICAL REPORTS, REPRINTS, AND FINAL REPORTS PUBLISHED BY OCEANOGRAPHIC CONTRACTORS \\ OF THE OCEAN SCIENCE AND TECHNOLOGY DIVISION \\ OF THE OFFICE OF NAVAL RESEARCH}

(REVISED NOVEMBER 1978)

1 Deputy Under Secretary of Defense

(Research and Advanced Technology)

Military Assistant for Environmental Science Room 3D129

Washington, D.C. 20301

Office of Naval Research

800 North Quincy Street

Arlington, VA 22217

3 ATTN: Code 483

1 ATTN: Code 460

2 ATTN: 102B

1 CDR J. C. Harlett, (USN)

ONR Representative

Woods Hole Oceanographic Inst.

Woods Hole, MA 02543

Commanding officer

Naval Research Laboratory

Washington, D.C. 20375

6 ATTN: Library, Code 2627
12 Defense Documentation Center Cameron Station

Alexandria, VA 22314

ATTN: DCA

Commander

Naval Oceanographic Office

NSTL Station

Bay St. Louis, MS 39522

1 ATTN: Code 8100

1 ATTN: Code 6000

1 ATTN: Code 3300

1 NODC/NOAA

Code D781

Wisconsin Avenue, N.W.

Washington, D.C. 20235 
UNCLASSIFIED $6 / 81$

18\30379122A.104

LCURITY CLASSIFICATION OF TMIS PAGE(Whon Date Entored)

20.

the predictions of simple linear, eddy viscosity models.

$B d-18=101)$

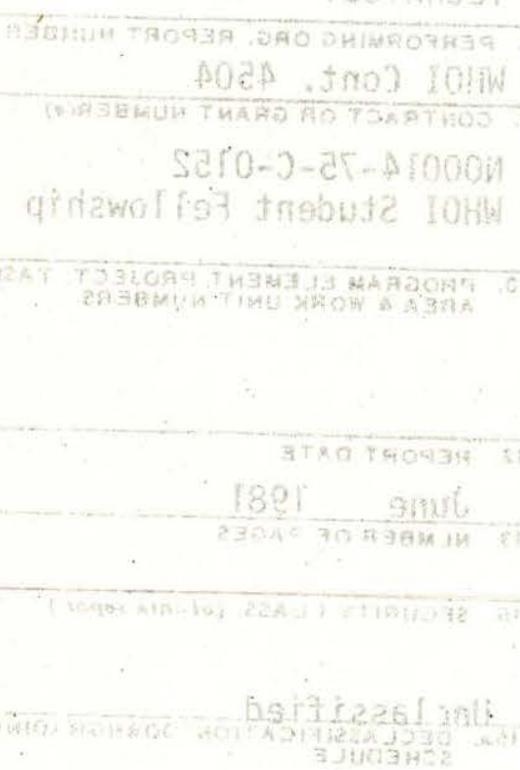

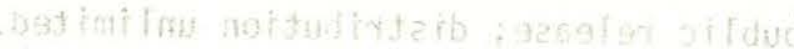
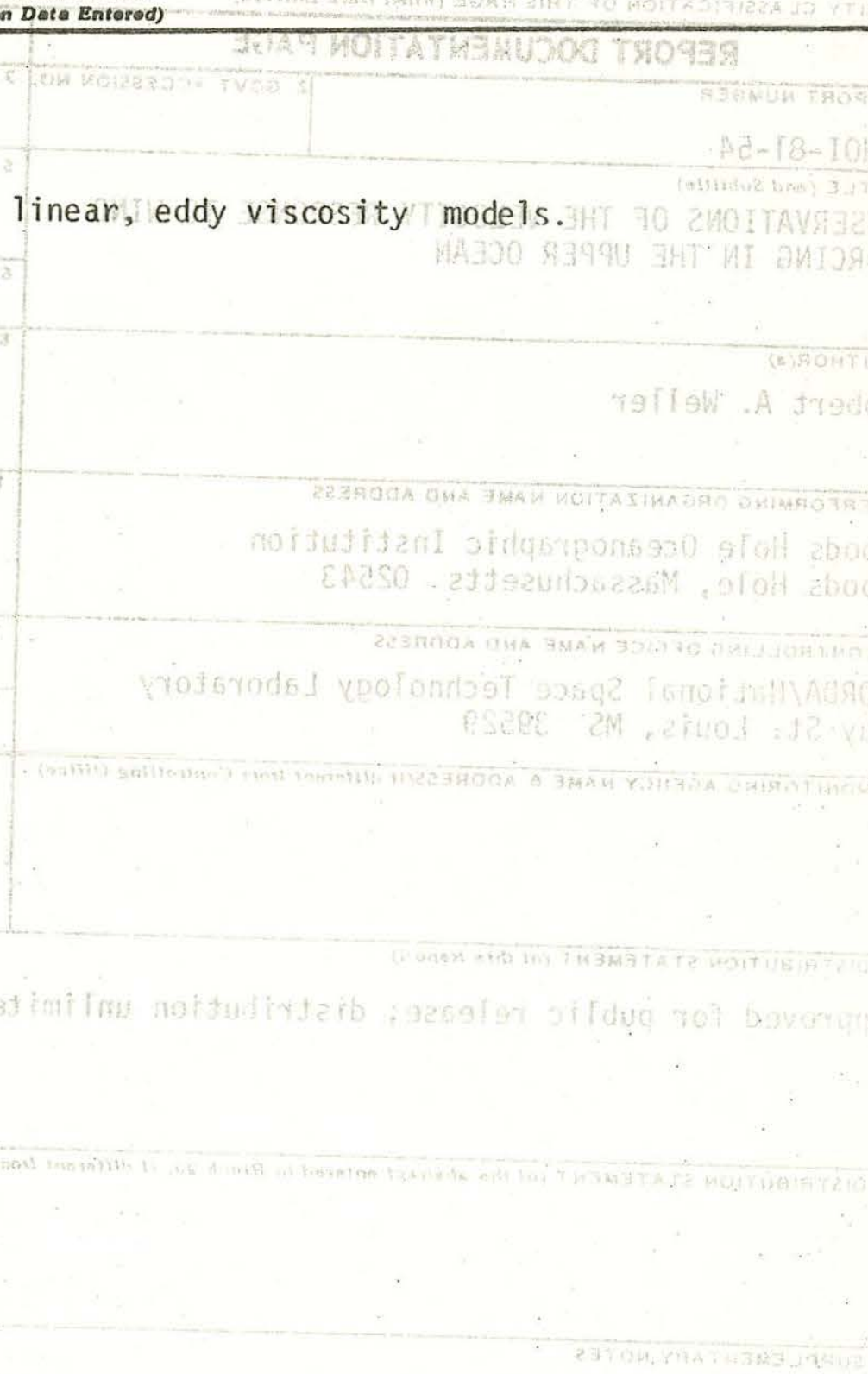

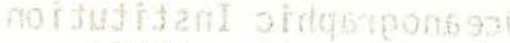

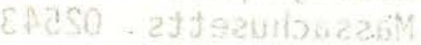

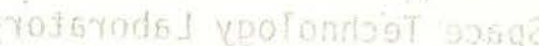

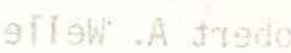




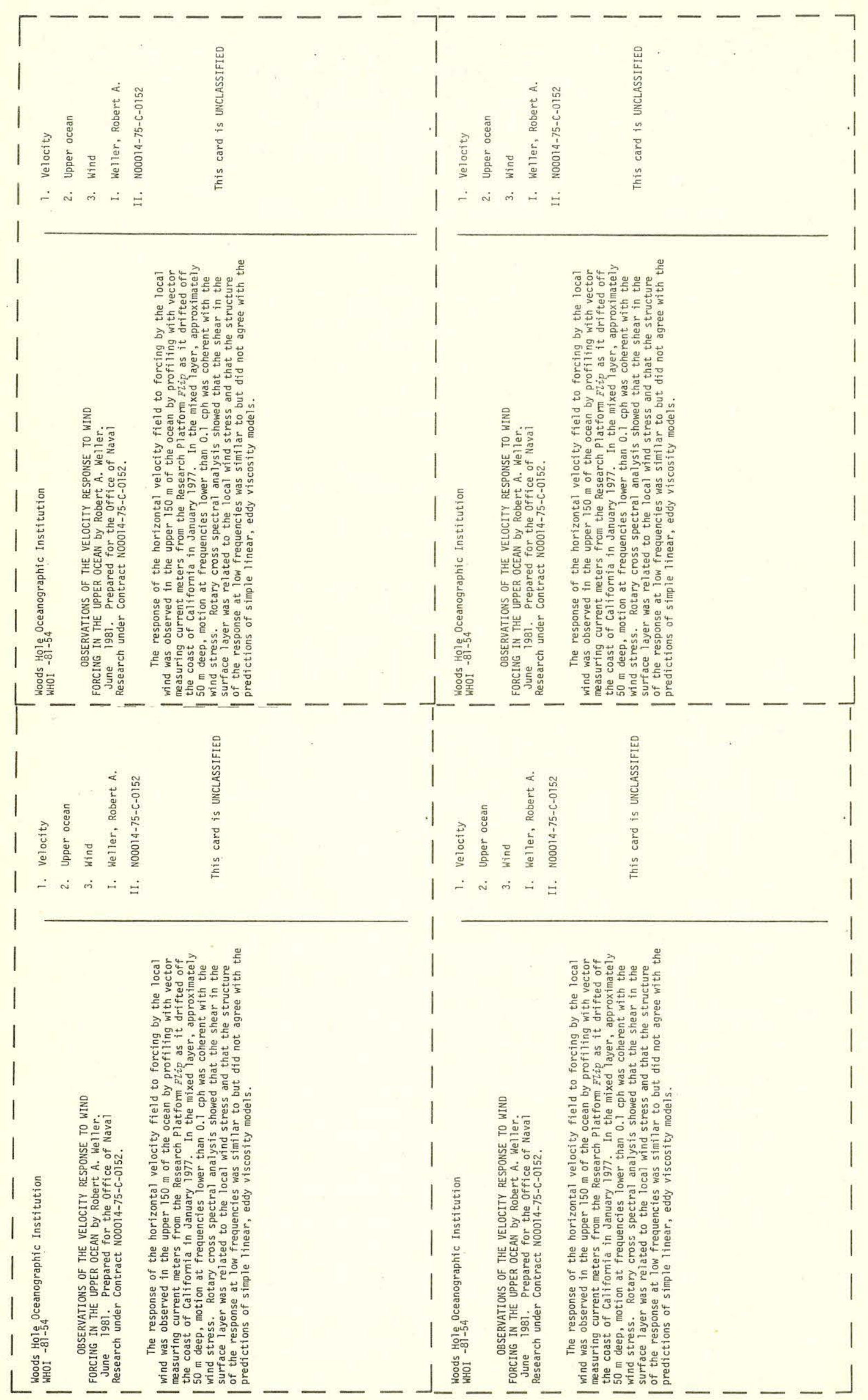

